Published in final edited form as:

Schizophr Res. 2013 March ; 144(0): 43-50. doi:10.1016/j.schres.2012.11.039.

\title{
Sexual dimorphisms and prediction of conversion in the NAPLS psychosis prodrome
}

\author{
Deborah J. Walder, \\ Brooklyn College \& The Graduate Center of The City University of New York \\ Carrie W. Holtzman, \\ Emory University \\ Jean Addington, \\ University of Calgary \\ Kristin Cadenhead, \\ University of California, San Diego \\ Ming Tsuang, \\ University of California, San Diego \\ Barbara Cornblatt, \\ Zucker Hillside Hospital \\ Tyrone D. Cannon, \\ Yale University \\ Thomas H. McGlashan, \\ Yale University
}

Scott W. Woods,

Yale University

Diana O. Perkins,

University of North Carolina, Chapel Hill

Larry J. Seidman,

Harvard Medical School

Robert Heinssen, and

National Institute of Mental Health

() 2012 Elsevier B.V. All rights reserved.

Corresponding Author: Deborah J. Walder, Ph.D., Department of Psychology, Room 5315 James Hall, Brooklyn College of The City University of New York, 2900 Bedford Avenue, Brooklyn, NY 11210, DWalder@brooklyn.cuny.edu, FAX: 718.951.4814, Phone: 718.951.5000.

Publisher's Disclaimer: This is a PDF file of an unedited manuscript that has been accepted for publication. As a service to our customers we are providing this early version of the manuscript. The manuscript will undergo copyediting, typesetting, and review of the resulting proof before it is published in its final citable form. Please note that during the production process errorsmaybe discovered which could affect the content, and all legal disclaimers that apply to the journal pertain.

Contributors: Authors JA, KC, MT, BC, TDC, THM, SWW, DOP, LS, RH and EFW designed the study and wrote the protocol. DJW and $\mathrm{CWH}$ conducted the literature searches and statistical analyses. DJW wrote the first draft of the manuscript. All authors contributed to the contents and approved the final manuscript. 


\section{Elaine F. Walker \\ Emory University}

\section{Abstract}

Sex differences in age at onset, symptomatology, clinical course (see Walker, Walder, Lewine and Loewy, 2002) and functional impairment (Thorup et al., 2007) are well documented in psychosis. The general pattern of findings is that males manifest an earlier onset, more severe symptoms and poorer prognosis than females. Limited studies examining individuals at clinical high-risk (CHR) suggest a similar pattern of sexual dimorphism (Holtzman et al., in review; Corcoran et al., 2011). As part of the North American Prodrome Longitudinal Study (NAPLS), the current study prospectively examined sexual dimorphisms differences in relationships among CHR symptoms, childhood (premorbid) academic and social functioning, baseline social and role functioning, and conversion to psychosis. Subjects included 276 (113F/163M) CHR NAPLS participants (ages 1236.8 years). All measures/criteria were assessed at baseline except conversion status, assessed at 6-month intervals up to 30 months. Results show sex differences in baseline social and role functioning (though not in early childhood adjustment) that predate psychosis onset, with sexually dimorphic patterns in relation to prodromal symptoms. Among male (but not female) CHRs, baseline social functioning and positive prodromal symptoms predicted conversion. These findings help elucidate early course of vulnerability for, and maximally sensitive and specific etiological and prediction models of, psychosis conversion. Findings highlight the importance of considering sexually differentiated predictors of longitudinal course and outcome, in the context of emerging risk profiles. This may optimize efforts at early identification and individually tailored preventive interventions targeting different neurobiological markers/systems and/or cognitivebehavioral approaches. We speculate a contemporary, multidimensional model of psychosis risk that posits a role of sexually dimorphic, genetically linked influences that converge with a modulating role of gonadal hormones (see Walder et al., 2012) across a temporally sensitive neurodevelopmental trajectory towards conferring risk.

\section{Keywords}

schizophrenia; sex differences; adolescence; at-risk; prognosis; vulnerability

\section{Introduction}

Sex differences in age at onset, symptomatology, and clinical course are well documented in the literature on schizophrenia and other psychoses (see Walker et al., 2002; Salem \& Kring, 1998; Seeman, 1982). Males tend to manifest an earlier onset, more severe negative symptoms, less severe affective symptoms, and poorer prognosis than females (see Walker et al., 2002). Among early competing theories explaining these sexually dimorphic patterns (see Castle et al., 1995) were those positing a protective role of gonadal hormones (e.g., Estrogen Hypothesis; see Hafner et al., 1991; Riecher-Rossler \& Hafner, 1993; Seeman \& Lang, 1990) versus subtypes of schizophrenia to which the sexes are differentially vulnerable (e.g., males more susceptible to a 'neurodevelopmental' subtype that yields a more prominent deficit syndrome) (Castle \& Murray 1991). More contemporary integrative models consider the complex interplay of these with factors such as sex differences in 
obstetric complications, psychosocial influences, stress sensitivity, genetic liability/familial transmission and gene expression, including from a neurodevelopmental perspective.

Although sex differences have not been studied as extensively in individuals at clinical highrisk (CHR) for psychosis, limited findings suggest a similar pattern of sexual dimorphism. Although several terms have been used to refer to samples identified to be at-risk based on clinical criteria (e.g., prodromal, ultra high-risk, clinical high-risk), the present paper uses $\mathrm{CHR}$ to refer to all high-risk samples. One recent report from the North American Prodrome Longitudinal Study (NAPLS) showed sex differences in baseline symptom severity in a large, CHR sample; high-risk males experienced more severe negative and disorganized symptoms, whereas positive and mood symptoms were not sexually differentiated (Holtzman et al., in review). Another smaller, recent CHR study also demonstrated more negative symptoms among high-risk males than females (Corcoran et al., 2011). These findings replicate and extend earlier retrospective findings from smaller high-risk and prodromal studies (Willhite et al., 2008).

Characterization of CHR phenomenology is of high priority given psychosis prevention strategies are limited by emphasis on late-emerging positive symptoms, which captures the period after disability is relatively well established (see Cornblatt et al., 2007, 2011). Better delineation of sexual differentiation during the prodrome holds important value towards 1) elucidating theoretical models including a dimensional perspective of psychosis-proneness (a la Meehl 1962), 2) understanding neurobiological underpinnings of psychosis and 3) refining existing multivariate models (e.g., Cannon et al., 2008) towards predicting who is at greatest risk for psychosis and in greatest need of intervention (see Holtzman et al., in review). In turn, this may implicate sexually differentiated strategies of identifying individuals at greatest risk for psychosis and preventive intervention.

Sexual dimorphisms in functional impairment are also well documented among psychotic patients, with more impaired social (Thorup et al., 2007) and premorbid (see Walker et al., 2002) functioning, as indicated by greater premorbid academic and occupational deficits (McGlashan \& Bardenstein 1990) among males. There is, however, a dearth of prospective studies examining sex differences in role functioning in CHRs. Thus, our understanding of sex differences in the longitudinal course and predictive power of premorbid functional deficits is limited. Yet, several reports demonstrate significant social and role functioning deficits in CHR (Cornblatt et al., 2011; Corcoran et al., 2011; Woods et al., 2009). Studies show conversion to psychosis is predicted by worse baseline functioning (Corcoran et al., 2011; Dragt et al., 2011; Yung et al., 2003; Tarbox et al., in review). Similarly, recent NAPLS studies revealed poorer childhood social functioning (Tarbox et al., in review), and baseline social (and to a lesser extent role) functioning (Cornblatt et al., 2011) predicted conversion to psychosis among CHRs. One CHR study found, despite no sex differences in symptoms or functioning, an interaction effect of recovery pattern. Women followed a progressive, sustained course of clinical improvement; whereas, among men, psychotic episode onset yielded faster and longer deterioration (Lemos-Giraldez et al., 2009). Overall, predominantly social, and to a lesser extent role, functioning deficits appear to be key conversion predictors in CHR samples. 
Similar to schizophrenia patients, there is some evidence that only negative symptoms in CHRs are associated with greater social (Corcoran et al., 2011; Cornblatt et al., 2007) and role (Cornblatt et al., 2007) functioning deficits, and school failure (Cornblatt et al., 2003). One CHR study, however, showed a relationship between more severe positive symptoms and global functioning deficits (Svirskis et al., 2007), and another concluded disorganized and general, nonspecific (but not positive or negative) symptoms are linked with more pronounced social functioning deficits (Shim et al., 2008). Inconsistencies may be attributable to heterogeneity in measures and/or sample characteristics. If study samples vary in sex ratio, and there are sex differences in the direction or strength of associations between symptoms and social/role functioning among CHRs, these may obscure the pattern of findings.

Further elucidation of sexual dimorphisms during the prodrome to psychosis, particularly among larger samples, is critical to understanding illness etiology and generating more powerful predictive models. Longitudinal studies of CHR samples, a substantial subgroup of who are 'true' prodromals, hold promise for elucidating sex differences in the antecedents and course of the prodrome to psychosis.

The current study examined sex differences in the relationships among symptoms, childhood academic and social functioning, baseline social and role functioning, and conversion to psychosis among CHR adolescents and young adults.

\section{Materials and Methods}

\subsection{Participants}

Participants included the subset of $276(113 \mathrm{~F} / 163 \mathrm{M})$ CHR NAPLS participants (ages 1236.8 years; $M=18.27, S D=4.64$ ) for whom at least partial data were available on measures of premorbid functioning (social adjustment, academic), current global functioning (social, role) assessed at baseline, and three symptom dimensions (positive, negative, disorganized) rated at baseline on the Structured Interview for Prodromal Symptoms (SIPS). The majority of the sample was Caucasian (77.2\%). Exclusion criteria for NAPLS included a history of a DSM-IV-TR Axis I psychotic disorder, mental retardation (accompanied by an IQ cutoff score of 70), or neurological disorder. Participants for whom follow-up data was not available at the 6-month assessment or later, or otherwise did not have conversion follow-up data were excluded. Forty-eight females (42.5\%) and 67 males (41.1\%) were on psychotropic medications at baseline (data were not available for 2 females and 11 males).

\subsection{Procedures}

Several measures assessing premorbid childhood academic and social functioning, baseline global (social, role) functioning, baseline prodromal symptomatology, prodromal criteria, and Axis I diagnostic criteria for DSM-IV were administered to all participants at the baseline assessment. After baseline assessment, patients were assessed for conversion status at 6-month intervals up to 30 months. 


\subsection{Measures}

\subsubsection{Structured Interview for Prodromal Symptoms (SIPS; Miller et al., 2002)}

- The SIPS was used to assess baseline prodromal symptomatology and longitudinal conversion status. The SIPS contains an instrument, the Scale of Prodromal Symptoms (SOPS), comprised of 29 items assessing positive, negative, disorganized and general symptom severity. This study examined the three key symptom dimensions (positive, negative, disorganized) that capture the cardinal features of psychosis. For each dimension, an index of average symptom severity was derived. Index ratings reflected the average score on a seven-point scale $(0-2=$ non-prodromal symptoms, $3-5=$ =prodromal level symptom, $6=$ psychotic level symptom).

2.3.2. Prodromal Criteria-To identify participants who met prodromal criteria, the Criteria of Prodromal Syndromes (COPS; Miller et al., 2002) were used. Prodromal syndromes include Attenuated Positive Symptom Syndrome (APSS), Genetic Risk and Deterioration Syndrome (GRDS), and Brief Intermittent Psychotic Syndrome (BIPS). APSS is characterized by the onset or worsening of sub-psychotic symptoms within the last 12 months, occurring with a frequency of at least once per week. GRDS entails the presence of a genetic risk for psychosis, defined by having a first-degree relative diagnosed with a psychotic disorder along with a decline of at least $30 \%$ in global functioning within the last 12 months. BIPS is characterized by positive symptoms of psychotic intensity that are brief in duration, recent and do not meet the threshold required for diagnosis of a psychotic disorder. Subjects diagnosed with schizotypal personality disorder (SPD) were also included in this sample, because SPD is genetically and developmentally linked with psychosis (Spitzer et al., 1994) and is now included as a prodromal syndrome (Dragt et al., 2011).

2.3.3. Conversion Status-Conversion to psychosis diagnosis was determined based on SIPS criteria positing the presence of sufficiently intense positive symptoms; either seriously disorganizing or dangerous, or present for at least half the days in a month, at least an hour per day. Possibly converting cases were interviewed with the SIPS and in some cases another structured diagnostic interview (e.g., Structured Clinical Interview for Diagnostic and Statistical Manual of Mental Disorders, $4^{\text {th }}$ Edition (SCID-I for DSM-IV; Siever 2003) to determine DSM-IV-TR psychotic disorder and comorbid diagnoses. The present study includes $70(30 \mathrm{~F} / 40 \mathrm{M} ; 34 \%)$ CHR participants who converted to psychosis at some point over a 2.5 year follow-up period. Conversion groups did not significantly differ in sex distribution (26.5\% of females; $24.5 \%$ of males; $x^{2}(1)=.142$, p >.10), race $\left(X^{2}(5)=5.293, p>\right.$. 10), or age (Converted:18.64(3.78); Nonconverted:18.14(4.90); $t(153.32)=-0.883, \mathrm{p}>.10)$.

2.3.4. Premorbid Adjustment Scale (PAS; Cannon-Spoor et al., 1982)—The PAS is a widely used semi-structured interview designed to retrospectively assess social and academic functioning prior to psychosis onset. The PAS has good predictive and concurrent validity in assessing premorbid functioning in schizophrenia (Brill et al., 2008). Each PAS item is interviewer rated on a 0-6 scale. The interview focuses on childhood (age 5-1 years), early adolescence (ages 12-5 years), late adolescence (ages 16-18 years), and adulthood (ages 19 years and above). For the current study, only childhood was examined, as data were available for the maximum number of participants, given all participants were at least 12 
years of age upon enrollment (at baseline). This optimized power to detect statistical significance. Mean PAS ratings were derived for the social functioning subscale (withdrawal, peer relationships), academic functioning subscale (scholastic performance, adaption to school) and total maladjustment subscale (social and academic ratings combined). The general information subscale was not utilized given the developmental emphasis of the stated hypotheses and concerns of bias against younger participants (van Mastrigt et al., 2002).

\subsubsection{Global Functioning: Social and Role Scales (Cornblatt et al., 2007)—}

These scales provide clinician-rated overall scores of current social and role functioning, similar in scope and design to the Global Assessment of Functioning Scale (GAF) and the Social and Occupational Functioning Assessment Scale (Goldman et al., 1992). These new well-anchored scales take age and phase of illness into account, which allows examination independent of clinical symptoms. The Social scale assesses quantity and quality of peer relationships, level of peer conflict, age-appropriate intimate relationships, and involvement with family members. The Role scale rates level of performance in the individual's primary role at school, at work or as homemaker. On both scales, scores range from 1 to 10 , with 1 indicating extreme dysfunction and 10 indicating superior functioning. For a more detailed description, see Cornblatt et al., 2007.

\subsection{Statistical analyses}

Analyses were performed using SPSS. Student's $t$-tests or Pearson's $\chi^{2}$ tests were used to test for sex differences in demographic characteristics and medication status. Between-sex differences and within-sex group differences (as a function of conversion status) in childhood adjustment and baseline global functioning were examined using independent samples $t$-tests. Pearson's $r$ correlational analyses were employed separately by sex to examine relationships among indices of childhood adjustment, global functioning and CHR symptoms. Fisher's $z$ transformation was used to standardize correlation coefficients and then compare correlation coefficients between $\operatorname{sex}(Z= \pm 1.65$ for $p<.05 ; Z= \pm 2.33$ for $p<.01$; 1-tailed). Logistic regression was employed separately by sex to provide an index of the predictive power of childhood adjustment, baseline global functioning and baseline CHR/ prodromal symptoms in predicting conversion status (yes/no) to Axis I psychotic disorder at follow-up (dichotomous outcome). Measure entry enabled assessment of the relative contribution of baseline global functioning and baseline CHR symptoms to conversion status above and beyond that contributed by childhood (social, academic) functioning. Covariates were not included given the absence of sex differences in age and medication status. Greater scores reflected better functioning and fewer symptoms, with exception of PAS whereby higher scores represented greater maladjustment. All tests were two-tailed, with alpha level set at .01 (to correct for multiple comparisons), unless otherwise noted. Trend level was set at $p<.05$, unless otherwise noted. 


\section{Results}

\subsection{Sex Differences in Childhood Adjustment}

There were no significant sex differences in childhood academic [M: 1.57(1.20), F: $1.27(1.25) ; t(220)=-1.81, p>.05]$, social [M: $1.57(1.43), \mathrm{F}: 1.62(1.30) ; t(222)=0.24, p>.05]$ or total [M: $0.26(0.19), \mathrm{F}: 0.24(0.17) ; t(221)=-0.84, p>.05]$ functioning.

\subsection{Sex Differences in Baseline Global Functioning}

Baseline social functioning (M: 5.88(1.57), F: 6.46(1.36); $t(273)=3.14, p=.002)$ and baseline role functioning (M: 5.92(1.76), F: 6.56(1.53); $t(274)=3.122, p=.002$ ) were significantly better in females than males.

\subsection{Relationships Among Childhood Adjustment, Baseline Symptoms \& Baseline Functioning By Sex}

3.3.1. Among females alone-As shown in Table 1, among females, neither childhood social, academic or overall adjustment was significantly associated with baseline social or role functioning ( $p>.05)$ or symptoms $(p>.05)$, although the relationship between childhood academic and overall functioning with disorganized symptoms was at trend level $(p<.05)$. As shown in Table 2, baseline negative $(p<.001)$ and disorganized $(p<.01)$ but not positive $(p>.05)$ symptoms were significantly inversely associated with baseline social functioning. Baseline negative and disorganized $(p<.001)$ but not positive $(p>.05)$ symptoms were significantly inversely associated with role functioning.

3.3.2. Among males alone-As shown in Table 1, among CHR males, poorer childhood social adjustment was significantly associated with poorer baseline social and role $(p<.01)$ functioning. Childhood academic functioning was not significantly associated with baseline social or role functioning $(p>.05)$. Childhood overall functioning was significantly associated with baseline social $(p<.05)$ and role $(p<.01)$ functioning. Childhood social adjustment among males was significantly associated with greater severity of positive ( $p<$. $01)$, negative $(p<.01)$, and disorganized $(p<.001)$ symptoms. Childhood academic adjustment was associated with positive symptoms at the trend level $(p<.05)$, but not negative or disorganized symptoms $(p>.05)$. Childhood overall functioning was significantly associated with positive, negative and disorganized symptoms $(p<.01)$. As shown in Table 2, baseline social and role functioning were significantly associated with baseline negative and disorganized $(p<.001)$ but not positive $(p>.05)$ symptoms.

\subsection{Sex Differences in Relationships Among Childhood Adjustment, Baseline Symptoms \& Baseline Functioning By Sex}

Between sex comparisons of the magnitude of Pearson correlations revealed no group differences, excepting the relationship of childhood social adjustment with baseline disorganized symptoms ( $z=1.648 ; p<.05 ; 1$-tailed) and baseline role functioning $(z=1.823$; $p<.05$; 1-tailed) at the trend level, and baseline social functioning with baseline disorganized symptoms $(z=1.789 ; p<.05 ; 1$-tailed) at the trend level. Thus, while the magnitude of the associations among measures of social functioning, role functioning and symptoms tended 
to be stronger for males than females, differences did not reach conventional levels of significance.

\subsection{Logistic Regression Prediction of Conversion Status by Sex}

As shown in Table 3, among female CHRs, neither childhood adjustment (social, academic), baseline global functioning (social, role), nor baseline prodromal symptoms (positive, negative, disorganized) were significant predictors of conversion status. In contrast, among male CHRs, baseline social functioning $(p<.05)$ and baseline positive prodromal symptoms $(p<.05)$ significantly predicted conversion. For these analyses, alpha level was set at .05 given there was no need to correct for multiple comparisons. See Figure 1a-1d.

\section{Discussion}

The present study indicates that some sex differences in symptoms and functioning observed in schizophrenia patients and other psychotic disorders also characterize CHRs. First, consistent with patient findings, our results suggest baseline social and role functioning are more impaired in CHR males than females. Contrary to expectation, early childhood academic, social and total adjustment were comparable between sexes. This may be due to self-report/response bias, given males tend to under-report symptoms such as depression (Sigmon et al., 2005). Alternatively, it is possible that impairment at this age may be too subtle to detect with available measures and/or these domains of functioning may be relatively spared until later development, when deterioration is observed during adolescence. Second, the pattern of relations among these variables is sexually dimorphic. The magnitude of the associations of childhood social adjustment with baseline disorganized symptoms and baseline role functioning, and baseline social functioning with baseline disorganized symptoms, tended to be stronger among males than females (though differences did not reach conventional levels of significance). This raises the possibility of subtle sex differences in prediction (and longitudinal course of symptoms/functioning) over time, as suggested by earlier findings of a more insidious and prolonged deterioration among males (Lemos-Giraldez et al., 2009). It is also possible that in a sample with females more evenly represented, findings would hold among females; this warrants clarification in future studies.

The present findings also parallel and extend prior findings indicating social and role functioning are key predictors of conversion among CHR youth (Cornblatt et al., 2011; Dragt et al., 2011; Yung et al., 2003; Tarbox et al., in review), and suggest the relationship may be stronger for males than females. Specifically, poorer baseline social functioning and baseline positive prodromal symptoms predicted significantly greater risk of conversion among males only, whereas no factor predicted conversion among females only.

One study limitation was a somewhat unequal distribution of participants at baseline by sex ( $40.1 \%$ female; $59.1 \%$ male), though the ratio was more even than in many earlier studies and was comparable by conversion status. One additional consideration (as noted by Holtzman et la., in review) is that diagnostic criteria for the prodrome require the presence of positive (but not negative, disorganized or general) symptoms in excess of a specified severity threshold, which may obscure sex differences involving examination of the positive prodromal symptom dimension. Thus, variability in positive symptom severity is 
constrained by the nature of the SIPS prodromal criteria. Future studies of sex differences in the prodrome will benefit from more comprehensive assessment across symptom dimensions.

Despite limitations, findings replicate and extend observed sex differences in psychosis and CHR samples. Results suggest sex differences in baseline global (social, role) functioning predate psychosis onset, with sexually dimorphic patterns in relation to prodromal symptoms and prediction of conversion to psychosis. Specifically, poorer baseline social functioning and positive prodromal symptoms predict greater conversion risk among males (not females). This extends literature demonstrating greater premorbid academic and occupational deficits among males with psychotic disorders (McGlashan et al., 1990), and greater symptomatology among males in domains linked with poorer prognosis and less responsiveness to antipsychotics (McGlashan \& Bardenstein, 1990; see Holtzman et al., in review).

Findings have implications for understanding the early course of vulnerability for, and etiology of, psychosis and highlight the importance of considering sexually differentiated predictors in the context of emerging risk profiles towards identifying individuals at greatest risk. Our findings largely support a dimensional model of psychosis-proneness, whereby patterns of sexual differentiation among CHR youth largely parallel that observed in patients, with few exceptions. Finding of comparable childhood academic, social and total adjustment between sexes may be attributable to self-report bias, masking an otherwise veritable, more insidious onset and prolonged deterioration among males, versus more precipitous course among females. It is possible that this absence of a sex difference may reflect a temporally sensitive developmental trajectory whereby sexual differentiation emerges not until adolescence.

What remains unclear are origins of sexually dimorphic prodromal clinical and functional manifestations of underlying illness and factors conjointly driving their persistence through the period of conversion to acute psychosis. The current findings do not clearly support one theoretical conceptualization or explanation. Rather, considered collectively with existing literature and emergent interdisciplinary work in the field, our findings likely point to a contemporary, multidimensional model of sexual differentiation in psychosis vulnerability that builds on earlier competing theories (see Castle et al., 1995; Hafner et al., 1991; Riecher-Rossler \& Hafner, 1993; Seeman \& Lang, 1990; Castle \& Murray 1991). Given recent evidence of sex-specific genetic associations in schizophrenia (for review, see Walder et al., 2012; Shifman et al., 2002), we speculate a role of sexually dimorphic genetically linked influences that may underlie sexually differentiated subtypes or manifestations of illness. Moreover, we conjecture a potential modulating role of gonadal hormones, as recently suggested in a non-clinical sample (Walder et al., 2012). This consideration is based on evidence that the prodrome (typically occurring during adolescence) is marked by dramatic alterations in neurohormonal milieus including cortisol, which is sexually differentiated (Kajantie \& Phillips 2006), is higher among at-risk youth who convert to psychosis (Walker et al., 2010), potentiates dopaminergic function (a la a neural diathesisstress model; Walker \& Diforio 1997), and is implicated in psychosis (Walder et al., 2000). 
This also extends earlier work positing a role of sex hormones in schizophrenia (Seeman \& Lang 1990) and schizophrenia risk (Walder et al., 2006).

Future investigations aimed at 1) delineating sexual dimorphisms at a finer level of analysis with respect to the nature, severity and longitudinal progression of global functioning and symptoms and 2) parallel examination of their relation to neurobiological vulnerability markers, hold promise towards elucidating etiological and prediction models of conversion that are maximally sensitive and specific. This may aid in development of individually tailored treatments, with consideration of sex effects (see Seeman 2012), which may target different neurobiological systems and/or use alternative cognitive/behavioral approaches with optimal effect.

\section{Acknowledgments}

Grant Funding \& Conflict of Interest (COI): Below is current grant and COI information. COI information pertaining to Larry Seidman and Kristin Cadenhead (along with any other updates/changes) will be updated/ provided at a later time.

Barbara Cornblatt: Self. NIMH: UO1MH081857-05. Consulting for Hoffman La Roche, 2012; Received royalties for the CPT-IP in 2010 - 12 which were paid directly to a general research account at Zucker Hillside Hospital.

Jean Addington: Self. NIMH: U01MH081984. Consultant. Hoffman La Roche.

Larry Seidman: Self. NIMH: U01 MH081928 P50 MH080272, 2 R01 MH065571 , RO1 MH078113, R21 MH091461, R01 HD067744, MH R21 MH092840, R21 MH093294, MH092440, R01 MH096027. None.

Larry Seidman: Self. Commonwealth of Massachusetts: SCDMH82101008006.

Kristin Cadenhead: Self. NIMH: R01 MH60720, U01 MH082022, K24 MH76191.

Diana Perkins: Self. NIMH: U01MH082004-01A1. Advisory Board: Sunovion DSMB, Genentech CNS, Genentech Mosaic Registry. Consultant: Telesage.

Elaine Walker: Self. NIMH: U01MH081988. None.

Scott Woods: Self. NIMH: U01MH082022, grants from Eli Lilly, Bristol Myers Squibb, Pfizer. Consultant. Merck.

Ty Cannon: Self. NIMH: MH081902. None.

Tom McGlashan: Self. NIMH R01 MH 50850.

Ming Tsuang: Self. NIMH U01 MH081944. None.

Robert Heinssen: None.

\section{References}

Brill N, Reichenberg A, Weiser M, Rabinowitz. Validity of the premorbid adjustment scale. Schizophr. Bull. 2008; 34:981-983. [PubMed: 18032397]

Cannon TD, Cadenhead K, Cornblatt B, et al. Prediction of psychosis in youth at high clinical risk: a multisite longitudinal study in North America. Arch. Gen. Psychiatry. 2008; 65:28-37. [PubMed: 18180426]

Cannon-Spoor HE, Potkin SG, Wyatt RJ. Measurement of premorbid adjustment in chronic schizophrenia. Schizophr. Bull. 1982; 8:470-484. [PubMed: 7134891]

Castle DJ, Abel K, Takei N, Murray RM. Gender differences in schizophrenia: hormonal effect or subtypes? Schizophr. Bull. 1995; 21:1-12. [PubMed: 7770731] 
Castle DJ, Murray RM. The neurodevelopmental basis of sex differences in schizophrenia. Psychol. Med. 1991; 21:565-575. [PubMed: 1946845]

Cornblatt BA, Auther AM, Niendam T, et al. Preliminary findings for two new measures of social and role functioning in the prodromal phase of schizophrenia. Schizophr. Bull. 2007; 33:688-702. [PubMed: 17440198]

Cornblatt BA, Carrion RE, Addington J, et al. Risk Factors for Psychosis: Impaired Social and Role Functioning. Schizophr. Bull. 2011 [e-pub ahead of print].

Cornblatt BA, Lencz T, Smith CW, Correll CU, Auther AM, Nakayama E. The schizophrenia prodrome revisited: A neurodevelopmental perspective. Schizoph. Bull. 2003; 29:633-651. [PubMed: 14989404]

Corcoran CM, Kimhy D, Parrilla-Escobar MA, et al. The relationship of social function to depressive and negative symptoms in individuals at clinical high risk for psychosis. Psychol. Med. 2011; 41:251-261. [PubMed: 20444306]

Dragt S, Niema DH, Veltman D, et al. Environmental factors and social adjustment as predictors of a first psychosis in subjects at ultra high risk. Schiz. Res. 2011; 125:69-76.

Goldman HH, Skodol AE, Lave TR. Revising axis V for DSM-IV: a review of measures of social functioning. Am. J. Psychi. 1992; 149:1148-1156.

Häfner H, Behrens S, De Vry J, Gattaz WF. An animal model for the effects of estradiol on dopaminemediated behavior: implications for sex differences in schizophrenia. Psychi. Res. 1991; 38:125134.

Holtzman C, Macdonald A, Esterberg M, et al. Sex differences in symptom presentation in individuals at ultra high risk for psychosis.

Kajantie E, Phillips DI. The effects of sex and hormonal status on the physiological response to acute psychosocial stress. Psychoneuroendocrin. 2006; 31:151-178.

Lemos-Giráldez S, Vallina-Fernández O, Fernández-Iglesias P, et al. Symptomatic and functional outcome in youth at ultra-high risk for psychosis: a longitudinal study. Schizophr. Res. 2009; 115:121-129. [PubMed: 19786339]

McGlashan TH, Bardenstein KK. Gender differences in affective,schizoaffective, and schizophrenic disorders. Schizophr. Bull. 1990; 16:319-329. [PubMed: 2374887]

Meehl PE. Schizotaxia, schizotypy, schizophrenia. Am. Psychologist. 1962; 17:827-838.

Miller TJ, McGlashan TH, Rosen JL, et al. Prospective diagnosis of the initial prodrome for schizophrenia based on the structured interview for prodromal syndromes: Preliminary evidence of interrater reliability and predictive validity. Am. J. Psychi. 2002; 159:863-865.

Riecher-Rössler A, Häfner H. Schizophrenia and oestrogens--is there an association? Eur. Arch. Psychiatry. Clin. Neurosci. 1993; 242:323-328.

Salem JE, Kring AM. The role of gender differences in the reduction of etiologic heterogeneity in schizophrenia. Clin. Psychol. Rev. 1998; 18:795-818. [PubMed: 9827322]

Seeman MV. Gender differences in schizophrenia. Can. J. Psychi. 1982; 27:107-112.

Seeman MV. Women and psychosis. Womens Health (Lond Engl). 2012; 8:215-224. [PubMed: 22375723]

Seeman MV, Lang M. The role of estrogens in schizophrenia gender differences. Schizophr. Bull. 1990; 16:185-194. [PubMed: 2197713]

Shifman S, Bronstein M, Sternfeld M, et al. A highly significant association between a COMT haplotype and schizophrenia. Am. J. Hum. Genet. 2002; 71:1296-1302. [PubMed: 12402217]

Shim G, Kang DH, Choi JS, et al. Prospective outcome of early intervention for individuals at ultrahigh-risk for psychosis. Earl. Interv. Psychi. 2008; 2:277-284.

Siever LJ. Refining the approaches to personality disorders. CNS Spectr. 2003; 8:724. [PubMed: 14712169]

Sigmon ST, Pells JJ, Boulard NE, et al. Gender differences in self-reports of depression: The response bias hypothesis revisited. Sex Roles. 2005; 53:401-411.

Spitzer, RL.; Williams, JB.; Gibbon, M. Instruction manual for the structured clinical interview for DSM-IV. New York, NY: Biometrics Research Department, New York State Psychiatric Institute; 1994. 
Svirskis T, Korkeila J, Heinimaa M, et al. Quality of life and functioning ability in subjects vulnerable to psychosis. Compr. Psychi. 2007; 48:155-160.

Tarbox S, Addington J, Cadenhead K, et al. Premorbid Functional Development and Conversion to Psychosis in Clinical High-Risk Youth.

Thorup A, Petersen L, Jeppesen P, et al. Gender differences in young adults with first-episode schizophrenia spectrum disorders at baseline in the Danish OPUS study. J. Nerv. Ment. Dis. 2007; 195:396-405. [PubMed: 17502805]

van Mastrigt S, Addington J. Assessment of premorbid function in first-episode schizophrenia: modifications to the Premorbid Adjustment Scale. J. Psychi Neurosci. 2002; 27(2):92-101.

Walder DJ, Andersson TLC, McMillan SM, Breedlove SM, Walker EF. Sex differences in finger digit ratio (2D:4D) are disrupted in adolescents with schizotypal personality disorder: Altered prenatal gonadal hormone levels as a risk factor. Schizophr. Res. 2006; 86:118-122. [PubMed: 16806835]

Walder, DJ.; Ospina, L.; Daly, MP.; Statucka, M.; Raparia, E. Early neurodevelopment and psychosis risk: Role of neurohormones and biological sex in modulating genetic, prenatal and sensory processing factors in brain development. In: Anastassiou-Hadjicharalambous, X., editor. Psychosis: Causes, Diagnosis and Treatment. Nova Science. 2012.

Walder DJ, Statucka M, Daly MP, Axen K, Haber M. Biological sex and menstrual cycle phase modulation of cortisol levels and psychiatric symptoms in a non-clinical sample of young adults. Psychiatry Res. 2012; 197:314-321. [PubMed: 22364929]

Walder DJ, Walker EF, Lewine RJ. Cognitive functioning, cortisol release, and symptom severity in patients with schizophrenia. Biol. Psychi. 2000; 48:1121-1132.

Walker EF, Brennan PA, Esterberg M, Brasfield J, Pearce B, Compton MT. Longitudinal changes in cortisol secretion and conversion to psychosis in at-risk youth. J. Abnorm. Psychol. 2010; 119:401-408. [PubMed: 20455612]

Walker EF, Diforio D. Schizophrenia: a neural diathesis-stress model. Psychol. Rev. 1997; 104:667685. [PubMed: 9337628]

Walker, EF.; Walder, DJ.; Lewine, R.; Loewy, R. Sex Differences in the Origins and Premorbid Development of Schizophrenia. Lewis-Hall, F.; Williams, TS.; Panetta, JA., editors. 2002.

Herrera, JH. Psychiatric Illness in Women: Emerging Treatments and Research. Washington, D.C.: American Psychiatric Publishing;

Willhite RK, Niendam TA, Bearden CE, Zinberg J, O'Brien MP, Cannon TD. Gender differences in symptoms, functioning, and social support in patients at ultra-high risk for developing a psychotic disorder. Schizophr. Res. 2008; 104:237-245. [PubMed: 18573639]

Woods SW, Addington J, Cadenhead K, et al. Validity of the prodromal risk syndrome for first psychosis: Findings from the North American prodrome longitudinal study. Schizophr. Bull. 2009; 35:894-908. [PubMed: 19386578]

Yung AR, Phillips LJ, Yuen HP, et al. Psychosis prediction: 12-month follow up of a high-risk (“prodromal”) group. Schizophr. Res. 2003; 60:21-32. [PubMed: 12505135] 
a.

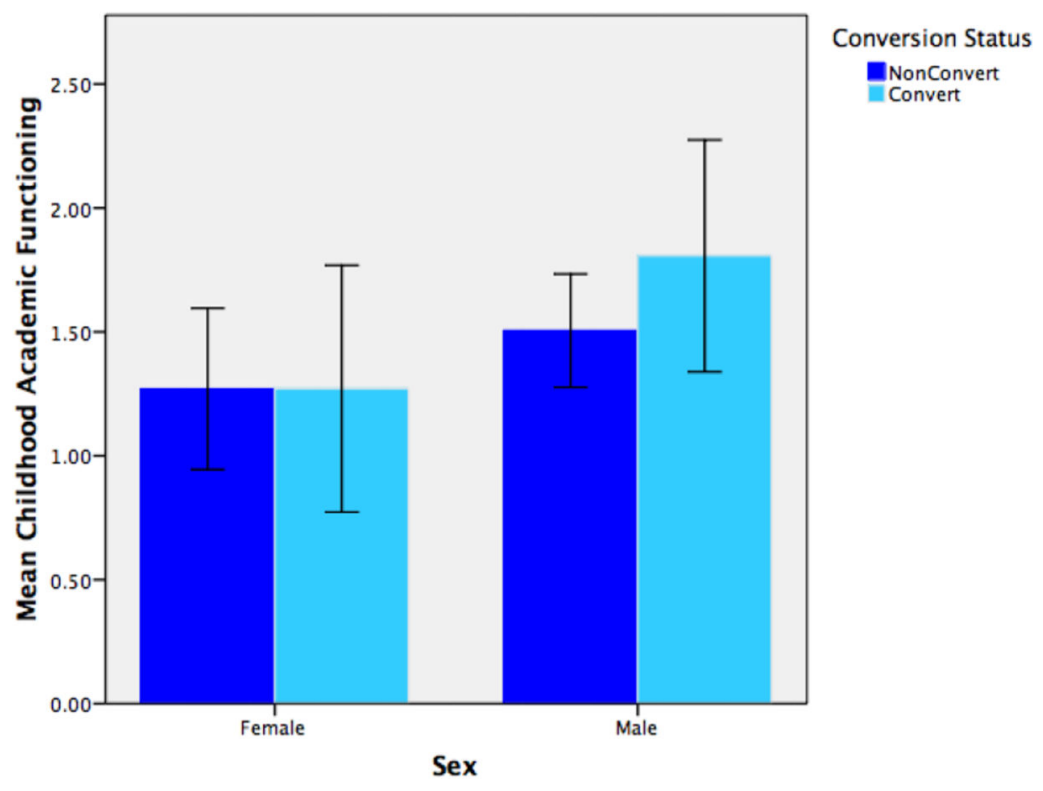

b.

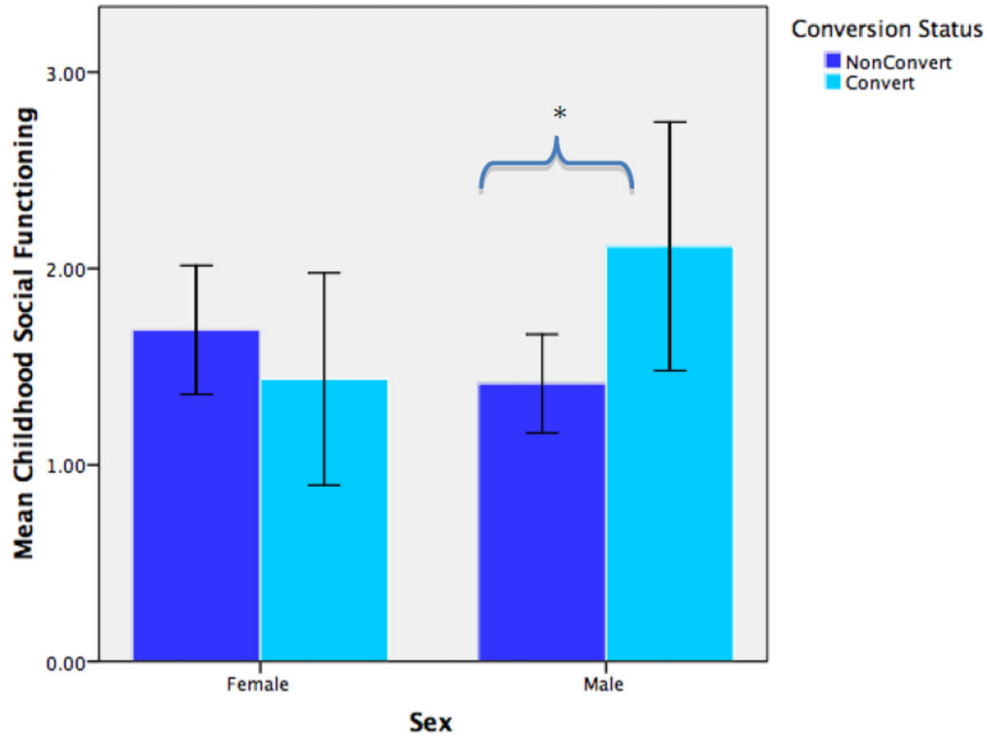

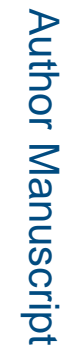




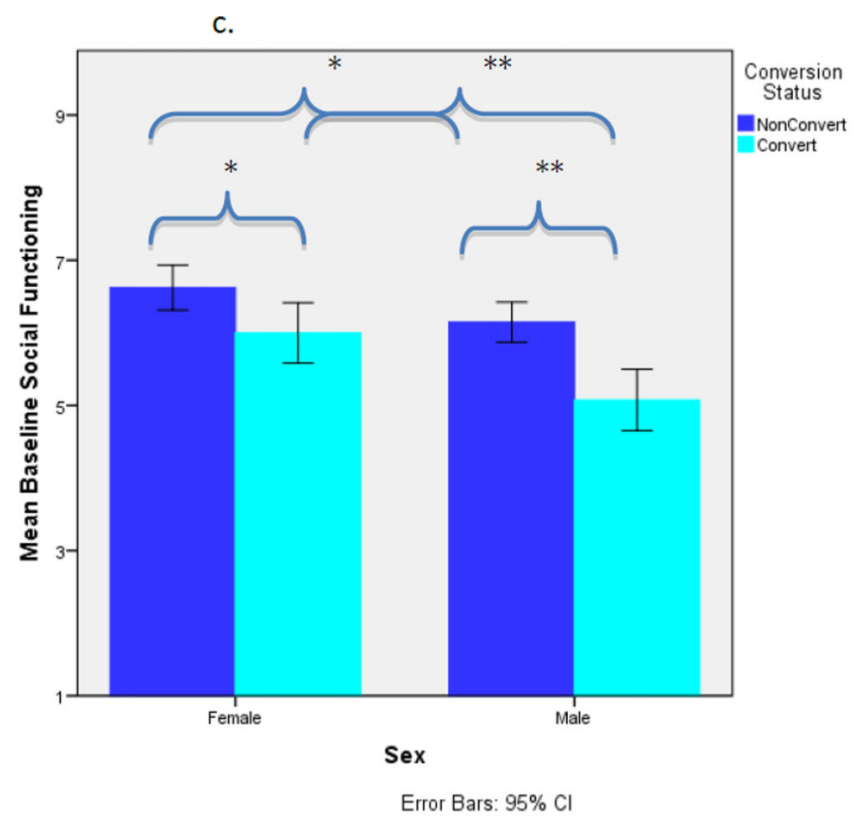

d.

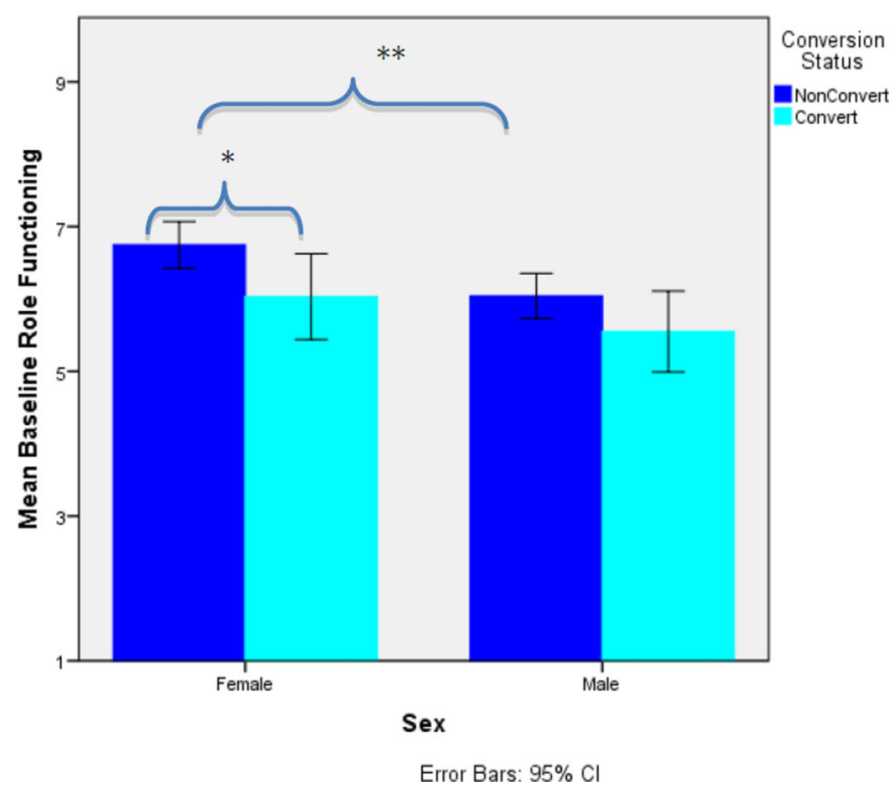

Figure 1.

a. Mean Childhood Academic Functioning by Conversion Status and Sex

b. Mean Childhood Social Functioning by Conversion Status and Sex

Note: Two-tailed; ** $\mathrm{p}<.01,{ }^{*} \mathrm{p}<.05$

c. Mean Baseline Social Functioning by Conversion Status and Sex

d. Mean Baseline Role Functioning by Conversion Status and Sex 


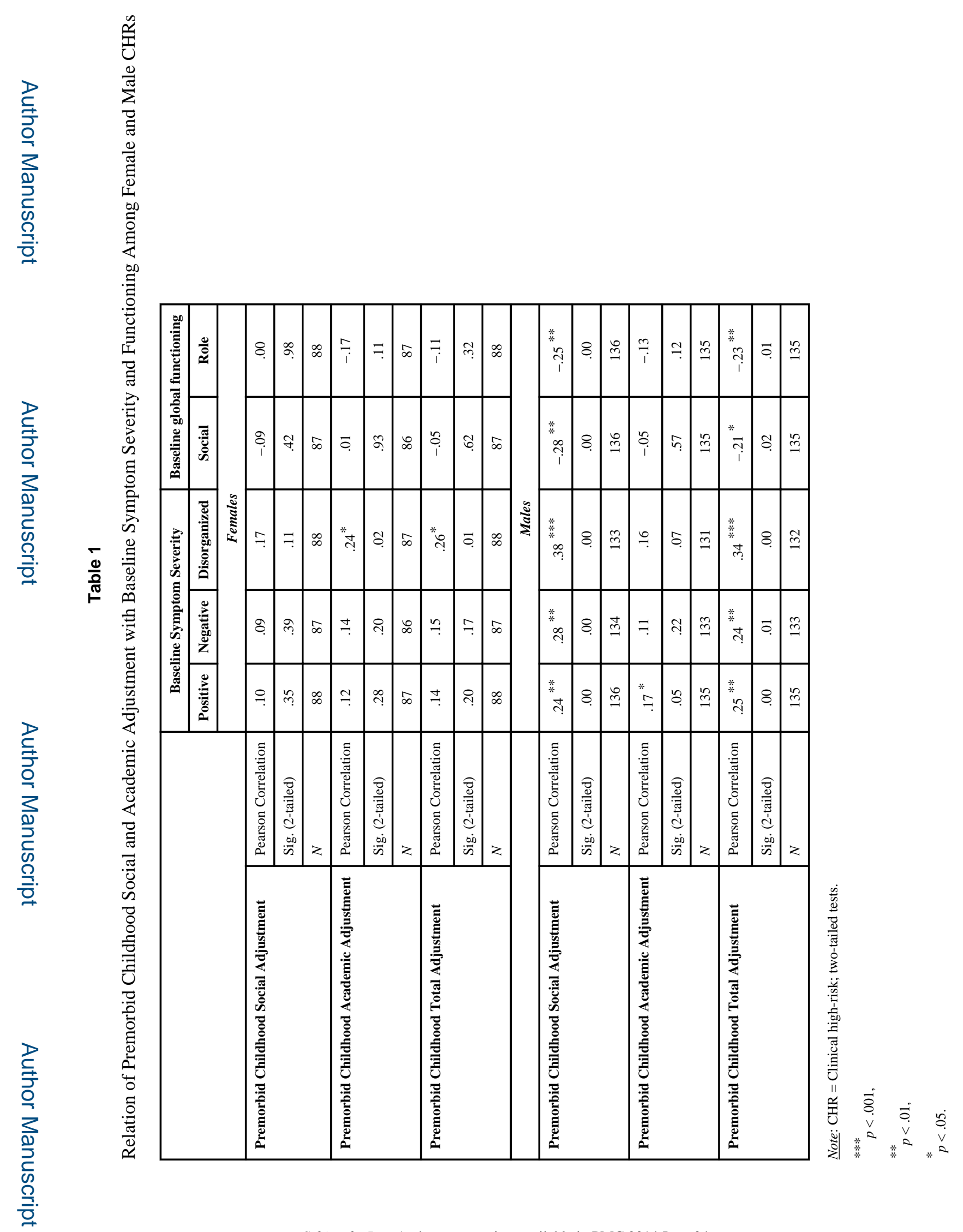

Schizophr Res. Author manuscript; available in PMC 2014 June 04. 
Table 2

Relationships Among Baseline Symptoms and Functioning Among Female and Male CHRs

\begin{tabular}{|c|c|c|c|c|}
\hline & & \multicolumn{3}{|c|}{ Baseline symptom severity } \\
\hline & & Positive & Negative & Disorganized \\
\hline & & \multicolumn{3}{|c|}{ Females } \\
\hline \multirow[t]{3}{*}{ Baseline Social Functioning } & Pearson Correlation & -.10 & $-.54 * * *$ & $-.28 * *$ \\
\hline & Sig. (2-tailed) & .32 & .00 & .00 \\
\hline & $N$ & 112 & 110 & 111 \\
\hline \multirow[t]{3}{*}{ Baseline Role Functioning } & Pearson Correlation & -.18 & $-.56^{* * *}$ & $-.40 * * *$ \\
\hline & Sig. (2-tailed) & .06 & .00 & .00 \\
\hline & $N$ & 113 & 111 & 112 \\
\hline & & \multicolumn{3}{|c|}{ Males } \\
\hline \multirow[t]{3}{*}{ Baseline Social Functioning } & Pearson Correlation & -.12 & $-.57^{* * *}$ & $-.47^{* * *}$ \\
\hline & Sig. (2-tailed) & .12 & .00 & .00 \\
\hline & $N$ & 163 & 160 & 159 \\
\hline \multirow[t]{3}{*}{ Baseline Role Functioning } & Pearson Correlation & -.11 & $-.58^{* * *}$ & $-.30 * * *$ \\
\hline & Sig. (2-tailed) & .18 & .00 & .00 \\
\hline & $N$ & 163 & 160 & 159 \\
\hline
\end{tabular}

Note: $\mathrm{CHR}=$ Clinical high-risk; two-tailed tests.

$* * *$

$p<.001$,

$* *$

$p<.01$,

$*$

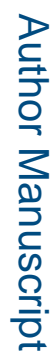

p $<.05$. 


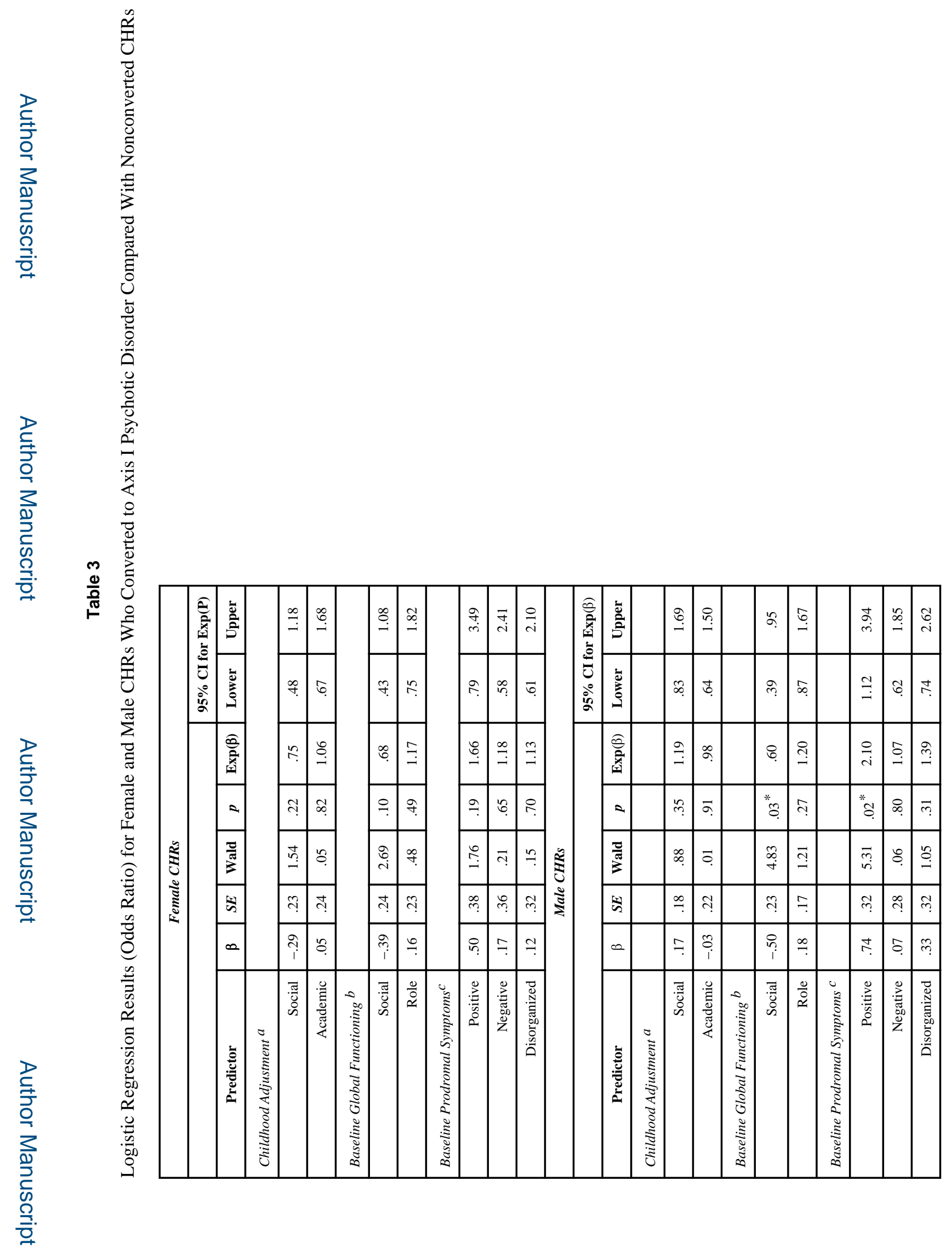

Schizophr Res. Author manuscript; available in PMC 2014 June 04. 

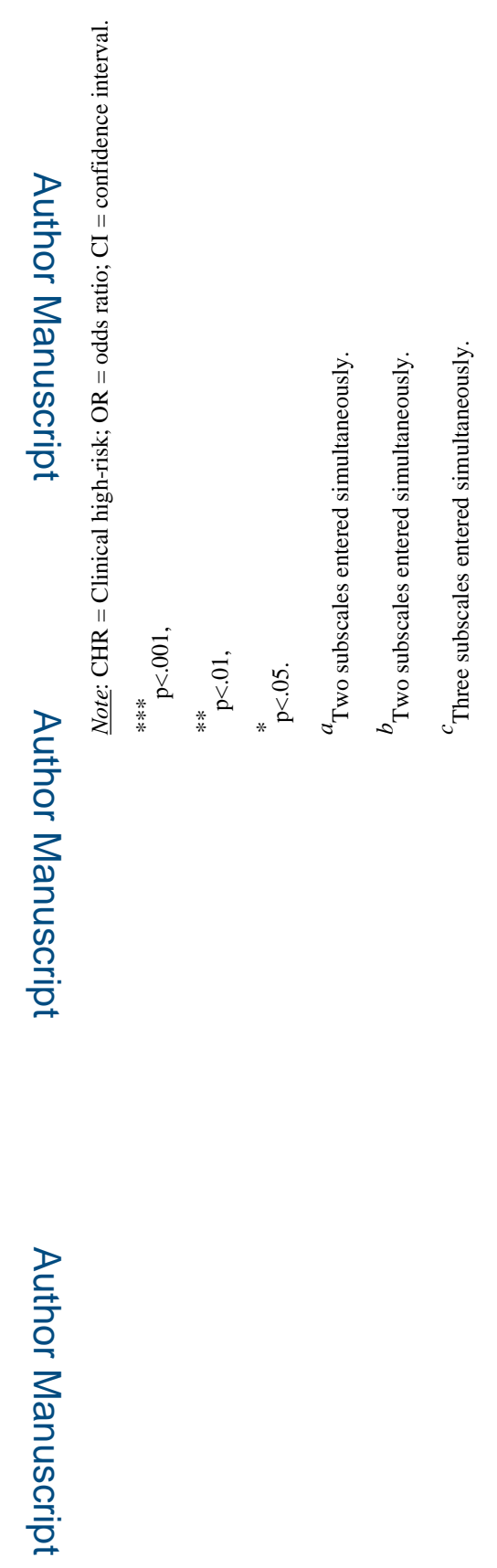

로을

Schizophr Res. Author manuscript; available in PMC 2014 June 04. 